\title{
Possibility of Removing Pb and Cd from Polluted Water by Modified Fly Ash
}

\author{
Xi Chen, ${ }^{1}$ Guibin Zhang, ${ }^{2}$ Jingtian $\mathrm{Li}^{3}$ and Puhui Ji $\mathbb{D}^{1}$ \\ ${ }^{1}$ College of Natural Resources and Environment, Northwest A\&F University, Yangling, Shaanxi 712100, China \\ ${ }^{2}$ Suzhou Suchuang Environmental Protection Technology Co., Ltd., Jiangsu 215100, China \\ ${ }^{3}$ The First Geological and Mineral Survey Institute of Henan Bureau of Geology and Mineral Exploration and Development, \\ Luoyang 471023, China
}

Correspondence should be addressed to Puhui Ji; jipuhui1983@163.com

Received 26 May 2021; Revised 21 June 2021; Accepted 25 July 2021; Published 13 August 2021

Academic Editor: Amit Kumar

Copyright (C) 2021 Xi Chen et al. This is an open access article distributed under the Creative Commons Attribution License, which permits unrestricted use, distribution, and reproduction in any medium, provided the original work is properly cited.

\begin{abstract}
In this study, fly ash (FA) was modified by sodium hydroxide to prepare a new adsorption material (IP) and treat $\mathrm{Pb}^{2+}-\mathrm{and} \mathrm{Cd}^{2+}-$ polluted wastewater. The effect of preparation parameters (mass ratio of $\mathrm{FA} / \mathrm{NaOH}$ and modification temperature) on IP adsorption performance was investigated. The results indicated that the IP4 showed the highest adsorption capacity prepared at the FA/ $\mathrm{NaOH}$ mass ratio of $1: 2$ and the roasting temperature of $250^{\circ} \mathrm{C}$. The IP4 was characterized by SEM, EDX, XRD, and FTIR analyses. The results showed that the surface morphology and microstructure of FA were significantly changed. Furthermore, in order to study the adsorption performance of $\mathrm{Pb}^{2+}$ and $\mathrm{Cd}^{2+}$ on IP4, the different initial concentrations of $\mathrm{Pb}^{2+}$ and $\mathrm{Cd}^{2+}, \mathrm{pH}$, and contact time were analyzed, and the results indicated that IP4 has excellent adsorption capacity for heavy metals. In addition, kinetic model results demonstrated that the adsorption behavior of $\mathrm{Pb}^{2+}$ and $\mathrm{Cd}^{2+}$ on IP4 was better described by a pseudo-second-order model.
\end{abstract}

\section{Introduction}

Among water resource problems, heavy metal ions have been considered the most serious pollutants [1], which can lead to tremendous damage to the ecosystem [2]. Lead $(\mathrm{Pb})$ and cadmium $(\mathrm{Cd})$ are considered the most dangerous heavy metals as they can induce some serious health problems [3]. Heavy metals accumulate in the organs of the human body through the food chain and further cause serious harm to human health [4].

Many technologies were introduced to treatment metal ions in wastewater, such as ion exchange [5], membrane separation [6], solvent extraction [7], and evaporation and chemical precipitation [8]. However, these technologies have limited applications due to their high cost and low efficiency [9]. Among these wastewater treatment methods polluted with heavy metals, the adsorption method was an effective and feasible method because of its low cost, simple operation, and high efficiency [10-12]. The key of adsorption technology is to prepare economical adsorbents with a large specific surface area and high adsorption efficiency. For example, activated carbon is used as heavy metal adsorbents, which presented excellent adsorption behavior due to its many macro- and micropores and large specific surface area [13]. However, those adsorbents perform escalating costs. In addition, there were many micropores on the activated carbon, which results in slow diffusion kinetics; thus, it is limited in wastewater treatment $[14,15]$. Thereby, it is imperative to develop new economical and efficient adsorbents, such as modified fly ash.

Coal fly ash (FA), a secondary product of coal burning in thermal power plants, is one of the most accessible and abundant anthropogenic materials [16]. The results of previous studies demonstrated that alkali-modified FA was an effective method in the adsorption and remediation of heavy metals (HMs) in water and soils $[17,18]$. Besides, $\mathrm{FA}$ is rich in silicon, which can improve the $\mathrm{HM}$ removal with $\mathrm{NaOH}$ addition $[19,20]$. However, there are few reports on adsorption of HMs for modified FA by low-temperature roasting assisted with sodium hydroxide. Therefore, the purpose of 
this study is to use a low-temperature roasting method to modify FA with $\mathrm{NaOH}$ as an activator and use modified fly ash to remove metal ions in wastewater compared to fly ash.

This study is aimed at investigating the possibility of using alkali-modified coal fly ash to remove $\mathrm{Pb}$ and $\mathrm{Cd}$. And the following key objectives were determined: (i) determine the best modification conditions of fly ash; (ii) characterize the modified fly ash with the best adsorption performance; (iii) study the influence of initial $\mathrm{pH}$, temperature, absorbing time, and initial concentrations of $\mathrm{Cd}^{2+}$ and $\mathrm{Pb}^{2+}$; and (iv) analyze the kinetic models.

\section{Methods and Materials}

2.1. Materials. Fly ash, used in the batch adsorption experiments, was collected from the Datong Power Plant, Shanxi Province. Chemical reagents used in this study include $\mathrm{HCl}$, $\mathrm{NaOH}, \mathrm{Cd}\left(\mathrm{NO}_{3}\right)_{2} \cdot 4 \mathrm{H}_{2} \mathrm{O}$, and $\mathrm{Pb}\left(\mathrm{NO}_{3}\right)_{2}$, and the above reagents were of analytical grade (GB/T 601-2016, Jinhuitaiya, China).

2.2. Preparation of IP. FA was dried in a constant temperature drying oven at $85^{\circ} \mathrm{C}$. Then, the material was mixed with $\mathrm{NaOH}$ in $1: 1$ and $1: 2$ proportions and the mixture was put in the nickel crucible, respectively, and then the nickel crucible was put in the muffle furnace and fired at $200^{\circ} \mathrm{C}$ for $2 \mathrm{~h}$. Finally, the samples were cooled to ambient temperature, and the $\mathrm{pH}$ of adsorbents was washed to neutral. The adsorbents prepared under the $1: 1$ and $1: 2$ proportions of FA : $\mathrm{NaOH}$ were marked IP1 and IP2, respectively.

Then, dried FA was mixed with $\mathrm{NaOH}$ in $1: 2$ proportion and the mixture was put in the nickel crucible, respectively. Then, the nickel crucible was put in the muffle furnace and fired at 150 and $250^{\circ} \mathrm{C}$ for $2 \mathrm{~h}$, respectively. Finally, the samples were cooled to ambient temperature, and the $\mathrm{pH}$ of samples was washed to neutral. The adsorbents prepared at the roasting conditions of 150 and $250^{\circ} \mathrm{C}$ were marked IP3 and IP4, respectively.

Initial $\mathrm{pH}$ of the solution was determined by a Mettler Toledo digital $\mathrm{pH}$ meter (calibrated using buffers of $\mathrm{pH}$ 4.01, 7.00, and 9.21), and FA and IP4 were analyzed through energy-dispersive X-ray (EDX), X-ray diffraction (XRD, D8 Advance), Fourier transform infrared (FTIR) spectroscopy (Nicolet iS10, Thermo Fisher Scientific), and scanning electron microscopy (SEM, S-4800, Hitachi Limited).

2.3. Adsorption Trial. The influence of different adsorption parameters on the adsorption of two metal ions was analyzed by batch adsorption experiments. Heavy metal-polluted wastewater was obtained using $\mathrm{Cd}\left(\mathrm{NO}_{3}\right)_{2} \cdot 4 \mathrm{H}_{2} \mathrm{O}$ and $\mathrm{Pb}\left(\mathrm{NO}_{3}\right)_{2}$. Dilute the $1000 \mathrm{mg} / \mathrm{L} \mathrm{Pb}^{2+}$ and $\mathrm{Cd}^{2+}$ solution to $100 \mathrm{mg} / \mathrm{L}$; then, $50 \mathrm{~mL} \mathrm{~Pb}^{2+}$ and $\mathrm{Cd}^{2+}$ solutions (the initial concentrations of two metal ions are both $100 \mathrm{mg} / \mathrm{L}$ ) were put in $250 \mathrm{~mL}$ Erlenmeyer flasks and mixed with $0.1 \mathrm{~g}$ of IP1, IP2, IP3, and IP4, respectively. Then, Erlenmeyer flasks were carried out on a shaker at $180 \mathrm{rpm}$ and continuously stirred for $60 \mathrm{~min}$ at $25^{\circ} \mathrm{C}$. After adsorption, the residual concentration of $\mathrm{Cd}^{2+}$ and $\mathrm{Pb}^{2+}$ in the filtrate was determined through an atomic absorption spectrometer (PinAAcle 900,
TABLE 1: Basic physicochemical properties of materials.

\begin{tabular}{lccccc}
\hline Material & $\mathrm{pH}$ & $\begin{array}{c}\text { Total Cd } \\
(\mathrm{mg} / \mathrm{g})\end{array}$ & $\begin{array}{c}\text { Total Pb } \\
(\mathrm{mg} / \mathrm{g})\end{array}$ & $\begin{array}{c}\text { Total Zn } \\
(\mathrm{mg} / \mathrm{g})\end{array}$ & $\begin{array}{c}\text { Total Cu } \\
(\mathrm{mg} / \mathrm{g})\end{array}$ \\
\hline FA & 8.57 & 0.31 & 26.4 & 58.4 & 25.6 \\
IP4 & 9.02 & 0.32 & 29.8 & 49.7 & 21.3 \\
\hline
\end{tabular}

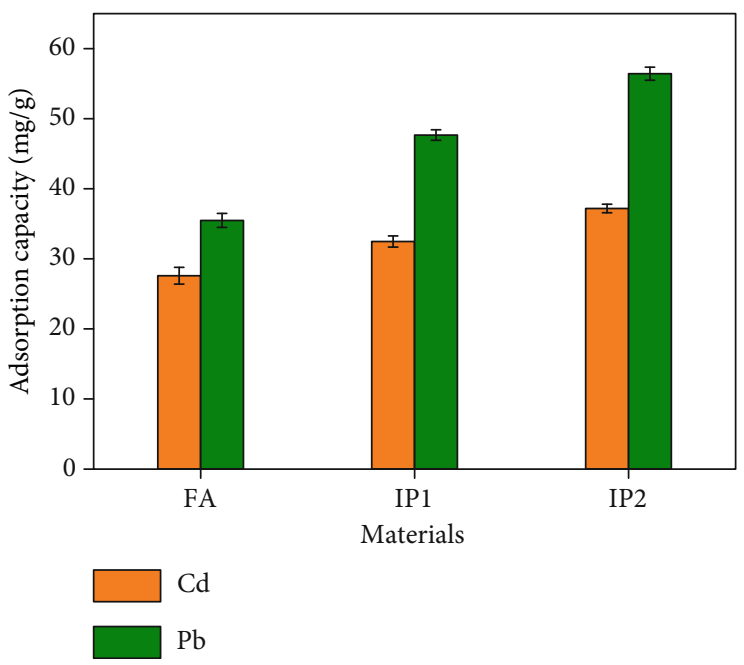

Figure 1: Adsorption of lead and cadmium by different fly ashalkali ratios of modified materials.

PerkinElmer). The material with the best adsorption performance was selected by comparing the adsorption capacity. The basic physicochemical properties of materials are shown in Table 1.

The removal efficiency $w(\%)$ and the adsorption capacity $q_{\mathrm{t}}$ $(\mathrm{mg} / \mathrm{g})$ were calculated as Equations (1) and (2), respectively.

$$
\begin{aligned}
& \omega=\frac{\left(C_{0}-C_{\mathrm{t}}\right)}{C_{0}} \times 100 \%, \\
& q_{\mathrm{t}}=\frac{\left(C_{0}-C_{\mathrm{t}}\right) V_{0}}{m},
\end{aligned}
$$

where $C_{0}$ and $C_{\mathrm{t}}$ represent the concentration of $\mathrm{Cd}^{2+}$ and $\mathrm{Pb}^{2+}$ before and after adsorption $(\mathrm{mg} / \mathrm{L})$, respectively; $m$ means material mass $(\mathrm{g})$; and $V$ is the volume $(\mathrm{mL})$.

\section{Results and Discussions}

\subsection{Effect of Preparation Parameters on IP Adsorption Capacity}

3.1.1. Effect of the FA/NaOH Mass Ratio. Figure 1 displays the effect of different $\mathrm{FA} / \mathrm{NaOH}$ mass ratios on the adsorption of $\mathrm{Pb}^{2+}$ and $\mathrm{Cd}^{2+}$. Compared with IP1 and IP2, FA had the lowest adsorption capacity for $\mathrm{Cd}^{2+}$, which was only $27.59 \mathrm{mg} / \mathrm{g}$, while the adsorption capacity for $\mathrm{Pb}^{2+}$ was $20 \%$ higher than that for $\mathrm{Cd}^{2+}$, indicating that the original fly ash had a certain adsorption capacity for $\mathrm{Pb}^{2+}$ and $\mathrm{Cd}^{2+}$. As can be seen, the adsorption amount of IP on both $\mathrm{Pb}^{2+}$ and $\mathrm{Cd}^{2+}$ was 

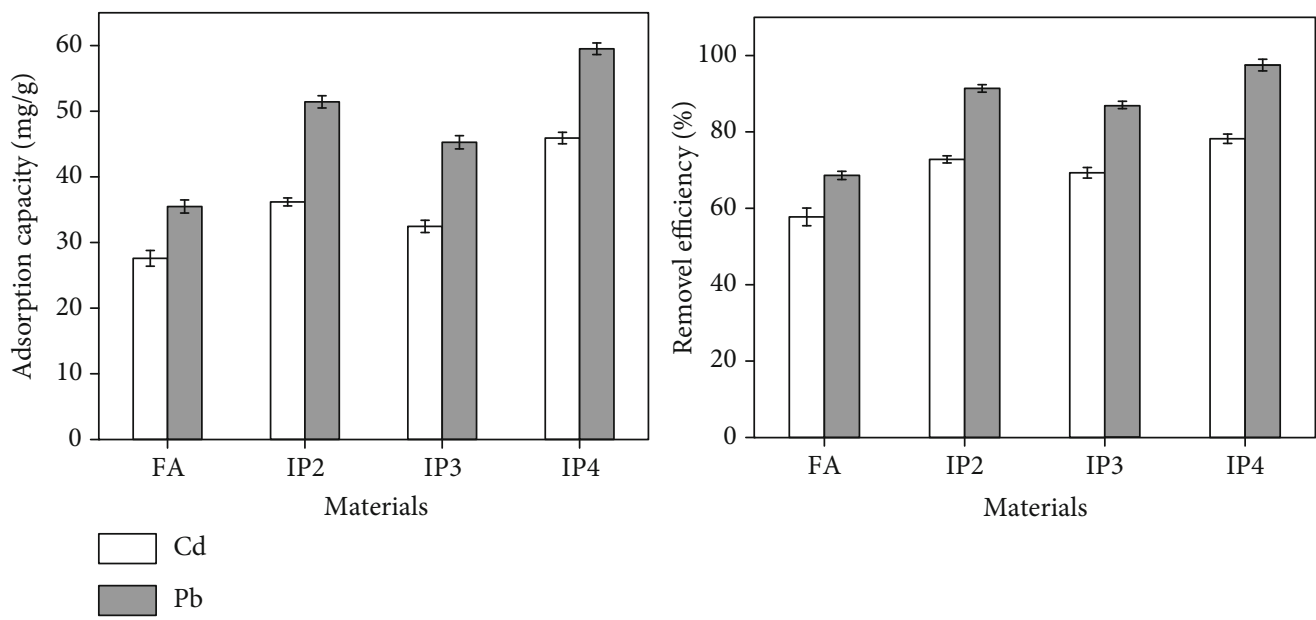

FIGURE 2: Adsorption amount of lead and cadmium (a) and removal efficiency of modified materials at different temperatures (b).

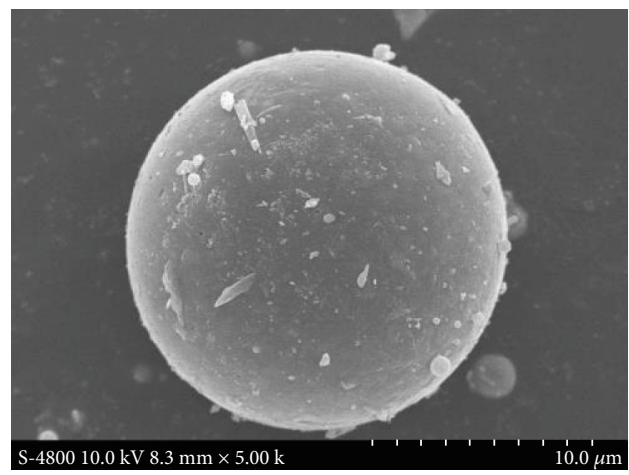

(a)

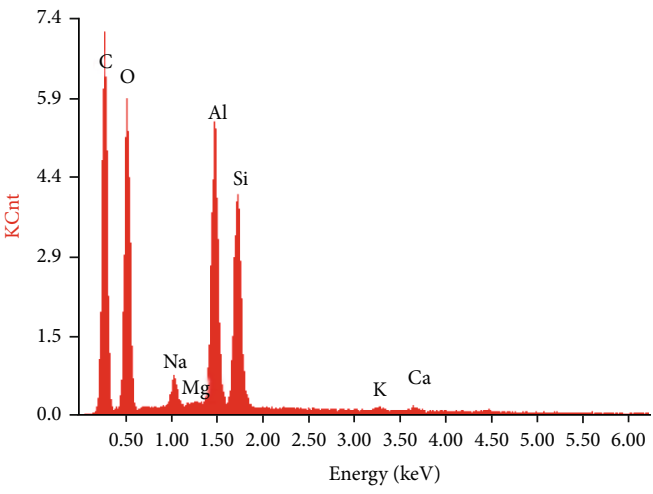

(c)

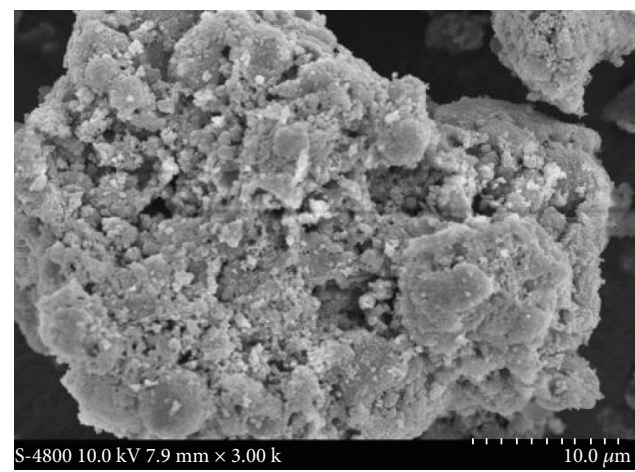

(b)

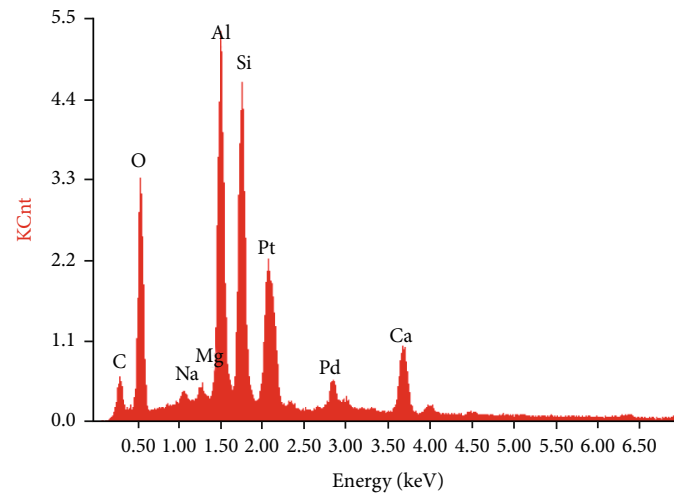

(d)

Figure 3: The SEM-EDX diagram of FA (a, c) and IP4 (b, d).

increased compared with that of fly ash, while the adsorption capacity of IP2 prepared at the FA/ $\mathrm{NaOH}$ mass ratio of $1: 2$ is stronger, possibly because the $\mathrm{OH}^{-}$can easily combine with heavy metal ions to form a more stable salt complex under alkaline conditions. It is precisely because of the participation of $\mathrm{NaOH}$ that the grain size of some minerals in the raw ash gradually decreases. The silicon and aluminum oxides can fully react with $\mathrm{NaOH}$ and play a good activation effect on the fly ash. Compared with the raw ash and IP1, IP2 has a better adsorption effect. Therefore, in the following preexperiment, the gray-base ratio of $1: 2$ will have a better effect.

3.1.2. Influence of Calcination Temperature. Figure 2 shows the adsorption amount and removal rate of two metal ions on FA and IPs prepared at different temperatures. From Figure 2(a), the adsorption capacity of two metal ions is higher on the three modified materials than FA, and the removal rate and adsorption capacity of adsorbents for 


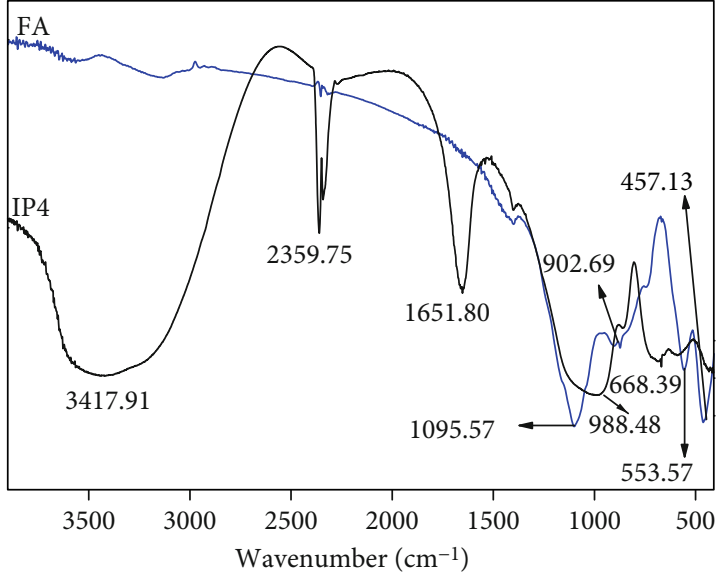

FIGURE 4: Infrared light map of FA and IP4.

$\mathrm{Pb}^{2+}$ and $\mathrm{Cd}^{2+}$ followed IP4 $>$ IP3 $>$ IP2 $>$ FA. The results indicated that increasing the modification temperature is conducive to the adsorption of the modified materials, which may be due to the reaction between the original fly ash and the $\mathrm{NaOH}$ being more adequate at $250^{\circ} \mathrm{C}$. For IP4, the adsorption capacities of $\mathrm{Pb}^{2+}$ and $\mathrm{Cd}^{2+}$ were 59.51 and $45.91 \mathrm{mg} / \mathrm{g}$, respectively, when the modification temperature is raised to $250^{\circ} \mathrm{C}$, which are $13.5 \%$ and $23.48 \%$ higher than that for IP2, respectively. As shown in Figure 2(b), the removal rate of $\mathrm{Pb}^{2+}$ reached $97.5 \%$ when the temperature rose to $250^{\circ} \mathrm{C}$, while the removal rate of $\mathrm{Cd}^{2+}$ was $78.21 \%$ under this condition, which was significantly higher than that of raw ash and IP3.

\subsection{Characteristics of Adsorbents}

3.2.1. SEM-EDX Analysis. The SEM-EDX images of FA and IP4 are displayed in Figure 3. As we can see from Figure 3(a), FA was characterized by a spherical structure with a smooth surface. However, after the modification, many fine particles appeared on the surface of the sample, IP4 had an irregularly shaped and amorphous particle structure, and the surface of the adsorbent becomes loose and porous. The results may be due to the fact that both $\mathrm{SiO}_{2}$ and $\mathrm{Al}_{2} \mathrm{O}_{3}$ were dissolved from the surface of $\mathrm{FA}$ with the $\mathrm{NaOH}$ treatment; the vitreous structure on the FA surface was also destroyed, which is beneficial to increase the specific surface area (BET) of the sample [21] and further improve the adsorption ability of metal ions. The BET and pore volume of the IP4 were $26.37 \mathrm{~m}^{2} / \mathrm{g}$ and $0.0017 \mathrm{~cm}^{3} / \mathrm{g}$, respectively, and its surface area was nearly 18 times larger than that of FA. Larger BET is more conducive to the improvement of adsorption capacity. This is mainly due to the rougher surface of IP4 with more vacancies for adsorption of heavy metals in case of producing more high-energy active sites on the surface. For the alkali roasting method making $\mathrm{Ca}$ and $\mathrm{Al}_{2} \mathrm{O}_{3}$ leach, its new chemical composition and surface structure got exposed, and the ability of being a heavy metal adsorbent is enhanced. While the size of particles got smaller, IP4 then had more extensive contact with heavy metal ions, which enhances the adsorption performance as

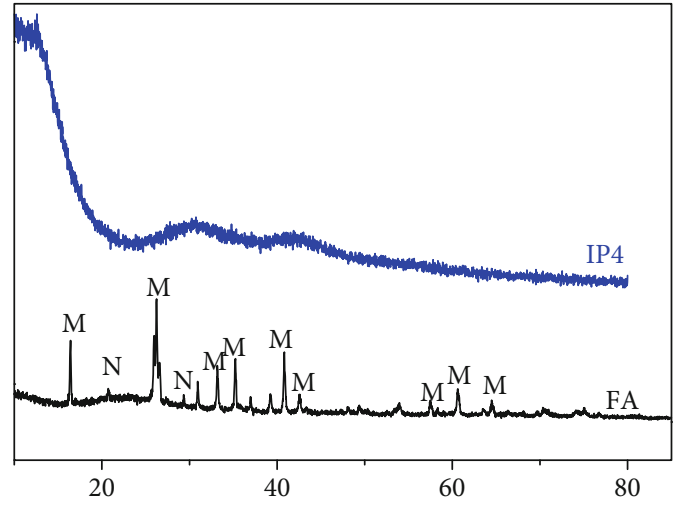

M-mullite

$\mathrm{N}$-quartz

Figure 5: The XRD pattern of FA and IP4.

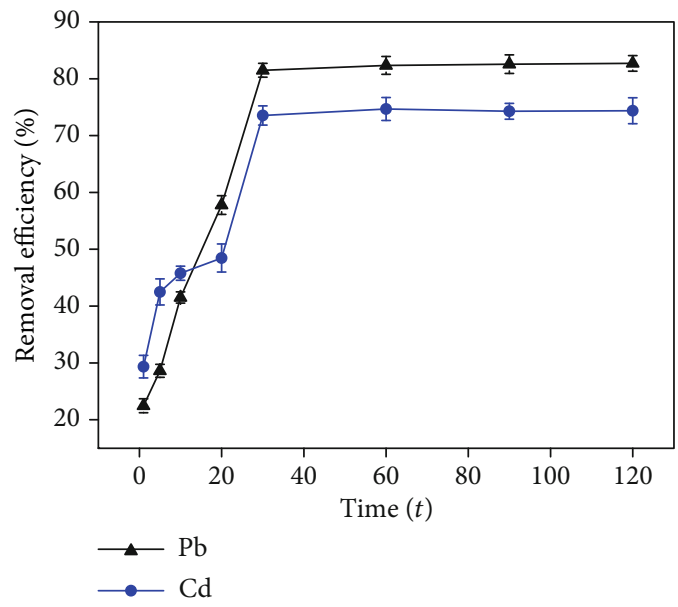

FIGURE 6: The influence of adsorption time on the removal rate of $\mathrm{Pb}^{2+}$ (a) and $\mathrm{Cd}^{2+}$ (b). Adsorption conditions: IP4 dosage: $0.05 \mathrm{~g}$; adsorption temperature: $25^{\circ} \mathrm{C}$; agitation speed: $180 \mathrm{rpm}$; initial $\mathrm{Cd}^{2+}$ concentration: $100 \mathrm{mg} / \mathrm{L}$; initial $\mathrm{Pb}^{2+}$ concentration: $150 \mathrm{mg} / \mathrm{L}$; and adsorption time: $0-120 \mathrm{~min}$.

well. Visa [22] reported a similar observation. As we can see from Figures 3(c) and 3(d), the main elements in the $\mathrm{FA}$ were $\mathrm{Al}, \mathrm{Si}$, and $\mathrm{O}$; after modification, $\mathrm{Al}, \mathrm{Si}$, and $\mathrm{O}$ were also the main elements of the IP4.

3.2.2. FTIR Analysis. The FTIR spectrum of FA and IP4 is performed in Figure 4. Four obvious intense and wide adsorption bands were found, which were located at $410 \sim 500 \mathrm{~cm}^{-1}$, $530 \sim 570 \mathrm{~cm}^{-1}, 800 \sim 910 \mathrm{~cm}^{-1}$, and $950 \sim 1200 \mathrm{~cm}^{-1}$, respectively. The adsorption peak that appeared at $457.13 \mathrm{~cm}^{-1}$ was ascribed to bending vibrations of $\mathrm{T}-\mathrm{O}(\mathrm{T}=\mathrm{Al} / \mathrm{Si})[23,24]$. The intense bands located at $1095.57 \mathrm{~cm}^{-1}$ were caused by the $\mathrm{TO}_{4}$ tetrahedral asymmetric vibrations [25]. After the modification, the position of the absorption bands was shifted to lower wavenumbers, and the intensity of the absorption peaks at $1095.57,902.69,553.57$, and $457.13 \mathrm{~cm}^{-1}$ was weakened. In the FTIR spectra of IP4, wide and intense adsorption 
TABLE 2: Kinetic model fitting parameters for $\mathrm{Cd}^{2+}$ and $\mathrm{Pb}^{2+}$ adsorption.

\begin{tabular}{lcccccrr}
\hline & & \multicolumn{3}{c}{ Pseudo-first-order } & \multicolumn{3}{c}{ Pseudo-second-order } \\
Metal ions & $q_{\mathrm{e}}(\mathrm{mg} / \mathrm{g})$ & $q_{\mathrm{e} \cdot \exp (\mathrm{mg} / \mathrm{g})}$ & $k_{1}(1 / \mathrm{min})$ & $R^{2}$ & $q_{\mathrm{e} \cdot \exp (\mathrm{mg} / \mathrm{g})}$ & $k_{2}(\mathrm{~g} / \mathrm{mg} 1 / \mathrm{min})$ & 0.0024 \\
\hline $\mathrm{Cd}^{2+}$ & 72.59 & 32.22 & 0.0082 & 0.8336 & 78.74 & 0.9928 \\
$\mathrm{~Pb}^{2+}$ & 122.74 & 65.75 & 0.013 & 0.8366 & 115.53 & 0.0013 \\
\hline
\end{tabular}

TABle 3: Comparison of previously reported $\mathrm{Cd}^{2+}$ and $\mathrm{Pb}^{2+}$ adsorption capacities of different adsorbents.

\begin{tabular}{lccc}
\hline \multirow{2}{*}{ Adsorbent } & \multicolumn{2}{c}{$\mathrm{Qm}(\mathrm{mg} / \mathrm{g})$} & Reference \\
& $\mathrm{Cd}^{2+}$ & $\mathrm{Pb}^{2+}$ & \\
\hline Ca-alginate bead & 1.26 & 1.74 & {$[2]$} \\
Camellia seed husk biochar & 45.6 & 113.2 & {$[3]$} \\
Modified orange peel & 13.7 & 73.5 & {$[5]$} \\
Chitosan-MAA material & 1.84 & 11.3 & {$[7]$} \\
Modified fly ash & 3.6 & 10.8 & {$[10]$} \\
IP4 & 78.74 & 115.5 & This study \\
\hline
\end{tabular}

bands were observed at 3417.91 and $1651.80 \mathrm{~cm}^{-1}$, respectively, which were attributed to $\mathrm{O}-\mathrm{H}$ stretching and $\mathrm{O}-\mathrm{H}$ bending $[26,27]$.

3.2.3. XRD Analysis. Figure 5 presents the XRD spectra for the FA and IP4, which suggested that the position of diffraction peaks was similar to that reported by Chen et al. [28]. The XRD results indicated that the mullite and quartz were the main components of FA, and the diffraction peak of mullite was mostly at around $2 \theta$ of $35^{\circ} \sim 38^{\circ}$. Compared with the spectra of FA and IP4, the spectrum of IP4 was completely different from FA, there were no mullite and quartz peaks on the IP4, and the curve of IP4 was relatively smooth and has no extra peaks. This result may be caused by the $\mathrm{SiO}_{2}$ and $\mathrm{Al}_{2} \mathrm{O}_{3}$ in the $\mathrm{FA}$ dissolved when modified by $\mathrm{NaOH}$ and may further form new soluble aluminosilicate compounds; then, that is, the raw coal fly ash was activated, which leads to the dissolution of the glass phase and the appearance of a new amorphous form.

The excellent performance of IP4 is mainly due to containing $\mathrm{Na}_{2} \mathrm{O}$ and $\mathrm{OH}^{-}$, both of which dissociate the Si-O and $\mathrm{Al}-\mathrm{O}$ peaks in the network structure with a higher degree of polymerization in FA; new unsaturated active bonds were constructed [21]. Under the action of the low-temperature roasting method with $\mathrm{NaOH}$, the crystal structure in FA not only was destroyed but also led to the dissociation reaction of $\mathrm{Al}_{2} \mathrm{O}_{3}, \mathrm{SiO}_{2}$, etc. To form active negatively charged groups, the acidic ions on the surface of FA $\left(\mathrm{H}^{+}\right)$will also be dissociated under alkaline conditions. In addition, the surface of the modified material is electronegative, which enhances the adsorption performance.

3.3. Influence of Adsorption Time. The influence of contact time on the removal efficiency of $\mathrm{Pb}^{2+}$ and $\mathrm{Cd}^{2+}$ is shown in Figure 6. As we can see from Figure 6, the removal rate of two metal ions was increased rapidly in the initial adsorp- tion period of $0 \sim 30 \mathrm{~min}$, and the adsorption equilibrium was basically reached at around $30 \mathrm{~min}$; after that, with the extension of time, the removal efficiency increased only slightly. When the adsorption time reached $120 \mathrm{~min}$, the removal rate of $\mathrm{Pb}^{2+}$ and $\mathrm{Cd}^{2+}$ was $82.71 \%$ and $74.37 \%$, respectively. This phenomenon may be due to the fact that there were many adsorption sites on the IP4 surface at the first period of adsorption; thus, the adsorption rate was fast [29]. With the reaction of adsorption sites and metal ions, available adsorption sites on the adsorbent surface were occupied, and the removal rate no longer changes significantly [30, 31].

The pseudo-first-order and pseudo-second-order models (Equations (3) and (4), respectively) were introduced to analyze the rate-controlling mechanism of the adsorption process [32].

$$
\begin{aligned}
\log \left(q_{\mathrm{e}}-q_{\mathrm{t}}\right) & =\log q_{\mathrm{e}}-\frac{\left(k_{1}\right) t}{2.303} \\
\frac{t}{q_{\mathrm{t}}} & =\frac{1}{k_{2} q_{\mathrm{e}}^{2}}+\frac{t}{q_{\mathrm{e}}}
\end{aligned}
$$

where $q_{\mathrm{t}}$ and $q_{\mathrm{e}}(\mathrm{mg} / \mathrm{g})$ were the adsorption amounts of $\mathrm{Pb}^{2+}$ and $\mathrm{Cd}^{2+}$ at adsorption time $t$ and at adsorption equilibrium, respectively, and $k_{1}(1 / \mathrm{min})$ and $k_{2}\left(\mathrm{~g} / \mathrm{mg} \cdot \mathrm{min}^{-1}\right)$ mean the adsorption rate constants.

The fitting results of adsorption kinetics are listed in Table 2. Obviously, the pseudo-second-order adsorption model showed higher correlation coefficients $\left(R^{2}\right)$, which demonstrated that the adsorption behavior of two metal ions on IP4 was better described by the pseudo-second-order model compared to the pseudo-first-order model. The results demonstrated that the adsorption behavior of metal ions on adsorbents was controlled by the rate-limiting step of chemisorption, as also research by Song et al. [33]. Moreover, the adsorption process has involved valence forces because of the exchange of electrons between IP4 and HMs [34]. Besides, the adsorption effect of IP4 is better than that of other materials, which can be used as an economical and environmentally friendly adsorbent for waste treatment (Table 3).

3.4. Influence of $\mathrm{pH}$ on Adsorption. The $\mathrm{pH}$ is a critical factor that influences the metal ion removal on the adsorbent. The effect of initial $\mathrm{pH}$ on the removal rate and adsorption amount is displayed in Figure 7. As we can see from Figures 7(a) and 7(b), the removal rate and adsorption capacity of $\mathrm{Pb}^{2+}$ and $\mathrm{Cd}^{2+}$ on IP4 significantly increased with the increasing $\mathrm{pH}$ from 2 to 6 and reached a plateau region at $\mathrm{pH}>6$. When the $\mathrm{pH}$ of the solution was low, excessive 


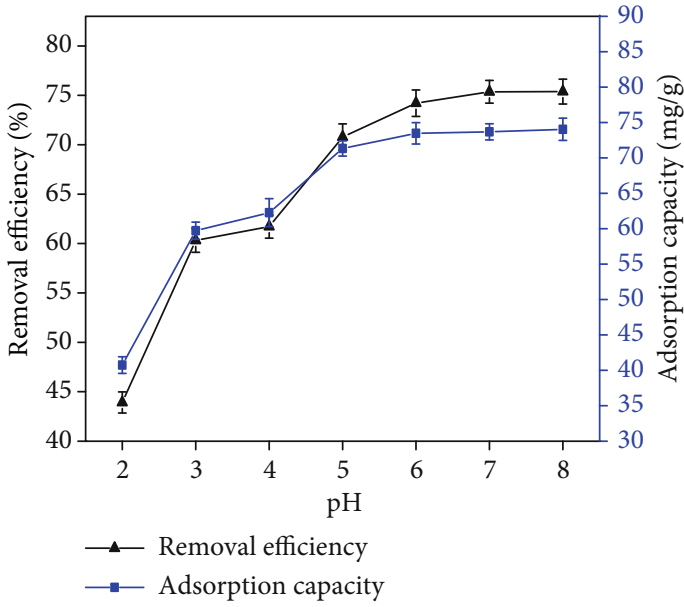

(a)

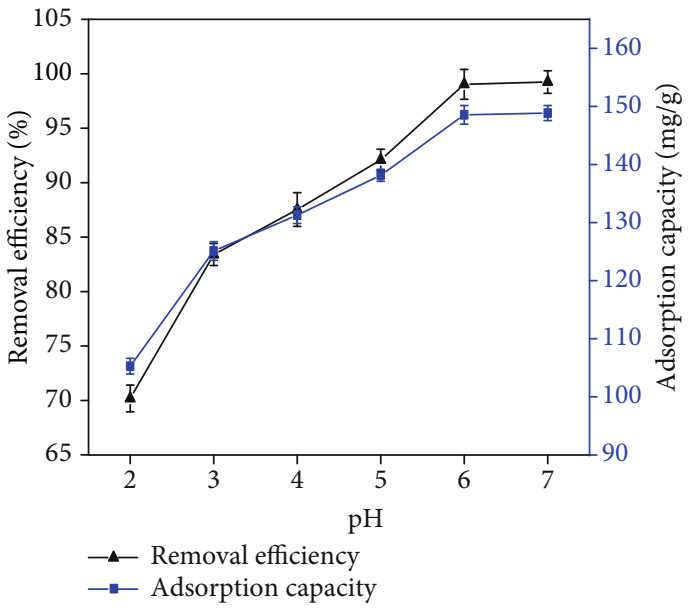

(b)

FiguRE 7: The effect of $\mathrm{pH}$ on the removal rate and adsorption capacity of $\mathrm{Cd}^{2+}(\mathrm{a})$ and $\mathrm{Pb}^{2+}(\mathrm{b})$. Adsorption conditions: IP4 dosage: $0.05 \mathrm{~g}$; adsorption time: $60 \mathrm{~min}$; adsorption temperature: $25^{\circ} \mathrm{C}$; agitation speed: $180 \mathrm{rpm}$; initial concentration of $\mathrm{Cd}^{2+}$ : $100 \mathrm{mg} / \mathrm{L}$; initial concentration of $\mathrm{Pb}^{2+}: 150 \mathrm{mg} / \mathrm{L}$; and solution $\mathrm{pH}: 2-8$.

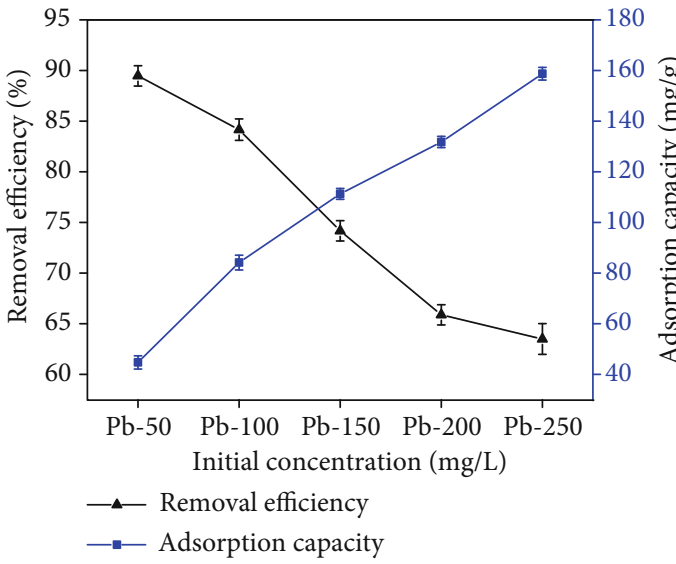

(a)

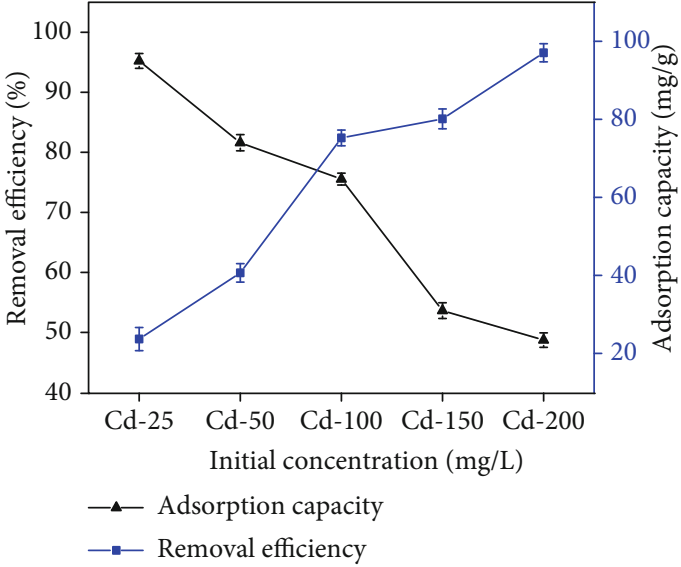

(b)

FIgURE 8: The influence of the initial concentration of heavy metals on the removal rate and adsorption amount of $\mathrm{Pb}^{2+}(\mathrm{a})$ and $\mathrm{Cd}^{2+}(\mathrm{b})$. Adsorption conditions: IP4 dosage: $0.05 \mathrm{~g}$; adsorption time: $60 \mathrm{~min}$; adsorption temperature: $25^{\circ} \mathrm{C}$; agitation speed: $180 \mathrm{rpm}$; initial Cd ${ }^{2+}$ concentration: $25-200 \mathrm{mg} / \mathrm{L}$; and initial $\mathrm{Pb}^{2+}$ concentration: $50-250 \mathrm{mg} / \mathrm{L}$.

hydrogen ions can compete with $\mathrm{Pb}^{2+}$ and $\mathrm{Cd}^{2+}$ for adsorption sites on the adsorbent surface. Therefore, the binding of heavy metals to the adsorption sites on the surface was limited $[35,36]$. The negative charge on the surface of the material increases with the increase in initial $\mathrm{pH}$, and the removal rate and adsorption capacity improved because of the electrostatic gravity force between the adsorption sites on the material surface and metal ions $[34,37]$. This observation is similar to others presenting that metal ion adsorption is more efficient in alkaline conditions. Besides, as we can see from Figure 7, the adsorption performance of IP4 to $\mathrm{Pb}^{2+}$ was higher than that to $\mathrm{Cd}^{2+}$, this may be due to the fact that the adsorption of metal ions was influenced by the hydrated radius [38] and the hydrated ionic radius of metal ions followed $\mathrm{Pb}^{2+}<\mathrm{Cd}^{2+}[39,40]$.
3.5. Effect of Initial Concentration. Figure 8 shows the influence of the initial concentration of $\mathrm{Pb}^{2+}$ and $\mathrm{Cd}^{2+}$ on the removal efficiency and adsorption capacity. As we can see from Figure 8, with the increase of the initial concentration of $\mathrm{Pb}^{2+}$ and $\mathrm{Cd}^{2+}$, the adsorption percentage of the two metal ions decreased. When the initial concentration of $\mathrm{Pb}^{2+}$ increased from 50 to $250 \mathrm{mg} / \mathrm{L}$ and that of $\mathrm{Cd}^{2+}$ increased from 25 to $200 \mathrm{mg} / \mathrm{L}$, the adsorption efficiency of $\mathrm{Pb}^{2+}$ and $\mathrm{Cd}^{2+}$ decreased from $89.47 \%$ to $63.49 \%$ and $95.23 \%$ to $48.72 \%$, respectively. This may be attributed to the fact that in the case of a fixed dosage, there were a large number of adsorption sites on the IP4 surface when the initial concentration of metal ions was low, and metal ions can fully react with the adsorption sites. Therefore, the removal rate is higher [41]. The adsorption sites were decreased with the 
increase of the concentration of two metal ions, and the adsorption rate is reduced. In addition, the adsorption amounts of two metal ions increased with the increase of the initial concentration. Besides, $\mathrm{Ca}^{2+}$ and $\mathrm{Mg}^{2+}$ contained in IP4 can be ion-exchanged with $\mathrm{Cd}^{2+}$, and the Si-O functional group on the surface of the material can also have a surface complexation reaction with metal ions [28].

\section{Conclusion}

In this study, the mass ratio of $\mathrm{FA} / \mathrm{NaOH}$ and the calcination temperature play a key role in the modification of FA. After low-temperature calcination modification of $\mathrm{NaOH}$, the new silicon-aluminum composite material IP obtains higher $\mathrm{Pb}^{2+}$ and $\mathrm{Cd}^{2+}$ adsorption capacity. Among them, IP4 (the $\mathrm{FA} / \mathrm{NaOH}$ mass ratio was $1: 2$; the calcination temperature was $250^{\circ} \mathrm{C}$ ) can be favored for heavy metal adsorption, compared with the other materials. The BET and pore volume of IP4 are increased, and the specific surface area is 18 times that of the original FA. The results of the characterization of IP4 show that IP4 mainly contains $\mathrm{Al}, \mathrm{Si}, \mathrm{O}$, and Na elements. $\mathrm{SiO}_{2}$ and $\mathrm{Al}_{2} \mathrm{O}_{3}$ on the surface of the $\mathrm{FA}$ are attacked, the glass phase on the surface is dissolved and destroyed, and then many new adsorption sites remain. The adsorption of two metal ions by IP4 is affected by initial concentration, solution $\mathrm{pH}$, and reaction time. In addition, adsorption results indicated that when the dosage was $0.05 \mathrm{~g}$, adsorption temperature was $25^{\circ} \mathrm{C}$, and the initial concentration of $\mathrm{Pb}^{2+}$ and $\mathrm{Cd}^{2+}$ was 150 and $100 \mathrm{mg} / \mathrm{L}$, respectively; the adsorption reached adsorption equilibrium at $30 \mathrm{~min}$, and the removal efficiency of $\mathrm{Pb}^{2+}$ and $\mathrm{Cd}^{2+}$ was 74.37 and $82.71 \%$, respectively. The adsorption capacity of IP4 for two metal ions followed $\mathrm{Pb}^{2+}>\mathrm{Cd}^{2+}$. The results of adsorption kinetic models demonstrated that the adsorption process of $\mathrm{Pb}^{2+}$ and $\mathrm{Cd}^{2+}$ by IP4 can be well described by a pseudo-secondorder model and the adsorption process was chemical adsorption based on ion exchange.

\section{Data Availability}

The basic mapping data used to support the findings of this study are available from the corresponding author upon request.

\section{Additional Points}

Highlights. (i) A new adsorbent has been successfully synthesized from fly ash. (ii) IP presents excellent adsorption capacity for heavy metals. (iii) Both the mass ratio and the temperature significantly affect the IP preparation. (iv) The adsorption efficiency of $\mathrm{Pb}^{2+}$ and $\mathrm{Cd}^{2+}$ was $82.71 \%$ and $74.37 \%$, respectively.

\section{Conflicts of Interest}

The authors declare that they have no conflicts of interest.

\section{Acknowledgments}

This work was supported by the Key Laboratory of Original Agro-environmental Pollution Prevention and Control, Ministry of Agriculture/Tianjin Key Laboratory of Agroenvironment and Safe-product Open Fund Project (Grant No. 17nybcdgj-2).

\section{References}

[1] Z. H. Yu, Y. F. Zhang, S. R. Zhai, Y. Wang, Y. Z. Pan, and C. G. Meng, "Amino-modified mesoporous sorbents for efficient $\mathrm{Cd}(\mathrm{II})$ adsorption prepared using non-chemical diatomite as precursor," Journal of Sol-Gel Science \& Technology, vol. 78, no. 1, pp. 110-119, 2016.

[2] S. K. Papageorgiou, F. K. Katsaros, E. P. Kouvelos, and N. K. Kanellopoulos, "Prediction of binary adsorption isotherms of $\mathrm{Cu}^{2+}, \mathrm{Cd}^{2+}$ and $\mathrm{Pb}^{2+}$ on calcium alginate beads from single adsorption data," Journal of Hazardous Materials, vol. 162, no. 2-3, pp. 1347-1354, 2009.

[3] J. W. Wu, T. Wang, Y. S. Zhang, and W. P. Pan, "The distribution of $\mathrm{Pb}(\mathrm{II}) / \mathrm{Cd}(\mathrm{II})$ adsorption mechanisms on biochars from aqueous solution: Considering the increased oxygen functional groups by $\mathrm{HCl}$ treatment," Bioresource Technology, vol. 291, p. 121859, 2019.

[4] L. V. A. Gurgel, O. K. Junior, R. P. Gil, and L. F. Gil, "Adsorption of $\mathrm{Cu}$ (II), $\mathrm{Cd}$ (II), and $\mathrm{Pb}$ (II) from aqueous single metal solutions by cellulose and mercerized cellulose chemically modified with succinic anhydride," Bioresource Technology, vol. 99, pp. 3077-3083, 2009.

[5] M. R. Lasheen, N. S. Ammar, and H. S. Ibrahim, "Adsorption/desorption of $\mathrm{Cd}(\mathrm{II}), \mathrm{Cu}(\mathrm{II})$ and $\mathrm{Pb}(\mathrm{II})$ using chemically modified orange peel: Equilibrium and kinetic studies," Solid State Sciences, vol. 14, no. 2, pp. 202-210, 2012.

[6] H. R. Mortaheb, A. Zolfaghari, B. Mokhtarani, M. H. Amini, and V. Mandanipour, "Study on removal of cadmium by hybrid liquid membrane process," Journal of Hazardous Materials, vol. 177, no. 1-3, pp. 660-667, 2010.

[7] A. Heidari, H. Younesi, Z. Mehraban, and H. Heikkinen, "Selective adsorption of $\mathrm{Pb}(\mathrm{II}), \mathrm{Cd}(\mathrm{II})$, and $\mathrm{Ni}$ (II) ions from aqueous solution using chitosan-MAA nanoparticles," International Journal of Biological Macromolecules, vol. 61, pp. 251-263, 2013.

[8] G. Bayramoglu, A. Denizli, S. Bektas, and M. Yakup Arica, "Entrapment of _Lentinus sajor-caju_ into Ca-alginate gel beads for removal of $\mathrm{Cd}(\mathrm{II})$ ions from aqueous solution: preparation and biosorption kinetics analysis," Microchemical Journal, vol. 72, no. 1, pp. 63-76, 2002.

[9] S. GUPTA and K. BHATTACHARYYA, "Removal of Cd(II) from aqueous solution by kaolinite, montmorillonite and their poly(oxo zirconium) and tetrabutylammonium derivatives," Journal of Hazardous Materials, vol. 128, no. 2-3, pp. 247257, 2006.

[10] E. Soo and J. Kalembkiewicz, "Comparison of adsorption of $\mathrm{Cd}(\mathrm{II})$ and $\mathrm{Pb}(\mathrm{II})$ ions on pure and chemically modified fly ashes," Chemical \& Process Engineering, vol. 37, pp. 215-234, 2016.

[11] S. R. Popuri, Y. Vijaya, V. M. Boddu, and K. Abburi, “Adsorptive removal of copper and nickel ions from water using chitosan coated PVC beads," Bioresource Technology, vol. 100, no. 1, pp. 194-199, 2009. 
[12] L. Semerjian, "Equilibrium and kinetics of cadmium adsorption from aqueous solutions using untreated_Pinus halepensis_ sawdust," Journal of Hazardous Materials, vol. 173, no. 1-3, pp. 236-242, 2010.

[13] J. Paul Chen and M. Lin, "Equilibrium and kinetics of metal ion adsorption onto a commercial H-type granular activated carbon: experimental and modeling studies," Water Research, vol. 35, no. 10, pp. 2385-2394, 2001.

[14] S. Y. Wang, M. H. Tsai, S. F. Lo, and M. J. Tsai, "Effects of manufacturing conditions on the adsorption capacity of heavy metal ions by Makino bamboo charcoal," Bioresource Technology, vol. 99, no. 15, pp. 7027-7033, 2008.

[15] X. S. Wang, H. H. Miao, W. He, and H. L. Shen, "Competitive adsorption of $\mathrm{Pb}(\mathrm{II}), \mathrm{Cu}(\mathrm{II})$, and $\mathrm{Cd}(\mathrm{II})$ ions on wheat-residue derived black carbon," Journal of Chemical and Engineering Data, vol. 56, pp. 444-449, 2017.

[16] A. F. Bertocchi, M. Ghiani, R. Peretti, and A. Zucca, "Red mud and fly ash for remediation of mine sites contaminated with $\mathrm{As}, \mathrm{Cd}, \mathrm{Cu}, \mathrm{Pb}$ and $\mathrm{Zn}$," Journal of Hazardous Materials, vol. 134, no. 1-3, pp. 112-119, 2006.

[17] H. Zhao, X. Huang, G. Zhang et al., "Possibility of removing cadmium pollution from the environment using a newly synthesized material coal fly ash," Environmental Science and Pollution Research, vol. 27, no. 5, pp. 4997-5008, 2020.

[18] X. Huang, H. Zhao, G. Zhang, J. Li, Y. Yang, and P. Ji, "Potential of removing $\mathrm{Cd}(\mathrm{II})$ and $\mathrm{Pb}(\mathrm{II})$ from contaminated water using a newly modified fly ash," Chemosphere, vol. 242, p. 125148, 2020.

[19] X. Querol, A. Alastuey, N. Moreno et al., "Immobilization of heavy metals in polluted soils by the addition of zeolitic material synthesized from coal fly ash," Chemosphere, vol. 62, no. 2 , pp. 171-180, 2006.

[20] L. Yang, X. Qian, P. Yuan et al., "Green synthesis of zeolite 4A using fly ash fused with synergism of $\mathrm{NaOH}$ and $\mathrm{Na}_{2} \mathrm{CO}_{3}$," Journal of Cleaner Production, vol. 212, pp. 250-260, 2019.

[21] R. Qiu, F. Cheng, and H. Huang, "Removal of $\mathrm{Cd}^{2+}$ from aqueous solution using hydrothermally modified circulating fluidized bed fly ash resulting from coal gangue power plant," Journal of Cleaner Production, vol. 172, pp. 1918-1927, 2018.

[22] M. Visa, "Synthesis and characterization of new zeolite materials obtained from fly ash for heavy metals removal in advanced wastewater treatment," Powder Technology, vol. 294, pp. 338-347, 2016.

[23] S. Onisei, Y. Pontikes, T. van Gerven et al., "Synthesis of inorganic polymers using fly ash and primary lead slag," Journal of Hazardous Materials, vol. 205-206, pp. 101-110, 2012.

[24] M. Criado, A. Fernández-Jiménez, and A. Palomo, "Alkali activation of fly ash: Effect of the $\mathrm{SiO}_{2} / \mathrm{Na}_{2} \mathrm{O}$ ratio: Part I: FTIR study," Microporous and Mesoporous. Materials, vol. 106, no. 1-3, pp. 180-191, 2007.

[25] L. Lin, S. Wang, and Z. Zhu, "Geopolymeric adsorbents from fly ash for dye removal from aqueous solution," Journal of Colloid and Interface Science, vol. 300, pp. 52-59, 2006.

[26] H. Yi and M. Han, "The influence of $\alpha-\mathrm{Al}_{2} \mathrm{O}_{3}$ addition on microstructure, mechanical and formaldehyde adsorption properties of fly ash-based geopolymer products," Journal of Hazardous Materials, vol. 193, pp. 90-94, 2011.

[27] L. Zheng, W. Wang, and Y. C. Shi, "The effects of alkaline dosage and $\mathrm{Si} / \mathrm{Al}$ ratio on the immobilization of heavy metals in municipal solid waste incineration fly ash-based geopolymer," Chemospher, vol. 79, no. 6, pp. 665-671, 2010.
[28] X. J. Chen, Y. X. Guo, F. Q. Cheng, H. P. Song, N. Zheng, and X. M. Wang, "Application of modified coal fly ash as an absorbent for ammonia-nitrogen wastewater treatment," Advanced Materials Research, vol. 518-523, pp. 2380-2384, 2012.

[29] Y. Zhang, W. J. Zhang, M. G. Dong, C. Z. Zhao, Q. X. Yang, and Z. J. Chen, "Preparation and adsorption properties of magnetic graphene foam for $\mathrm{Cu}\left({ }^{2+}\right)$," Fine Chemicals, vol. 35, pp. 10-16, 2018.

[30] M. Q. Jiang, X. Y. Jin, X. Q. Lu, and Z. L. Chen, “Adsorption of $\mathrm{Pb}(\mathrm{II}), \mathrm{Cd}(\mathrm{II}), \mathrm{Ni}(\mathrm{II})$ and $\mathrm{Cu}(\mathrm{II})$ onto natural kaolinite clay," Desalination, vol. 252, no. 1-3, pp. 33-39, 2010.

[31] B. Thakur, G. Sharma, A. Kumar et al., "Designing of bentonite based nanocomposite hydrogel for the adsorptive removal and controlled release of ampicillin," Journal of Molecular Liquids, vol. 319, p. 114166, 2020.

[32] J. Y. Liu, C. W. Hu, and G. G. Huang, "Adsorption of $\mathrm{Cu}^{2+}$, $\mathrm{Pb}^{2+}$, and $\mathrm{Cd}^{2+}$ onto oiltea shell from water," Bioresource Technology, vol. 271, pp. 487-491, 2019.

[33] Y. C. Song, L. Y. Yang, Y. G. Wang, D. Yu, J. Shen, and X. K. Ouyang, "Highly efficient adsorption of $\mathrm{Pb}$ (II) from aqueous solution using amino- functionalized SBA-15/calcium alginate microspheres as adsorbent," International Journal of Biological Macromolecules, vol. 125, pp. 808-819, 2019.

[34] P. Dhiman, S. Sharma, A. Kumar, M. Shekh, G. Sharma, and M. Naushad, "Rapid visible and solar photocatalytic $\mathrm{Cr}(\mathrm{VI})$ reduction and electrochemical sensing of dopamine using solution combustion synthesized $\mathrm{ZnO}-\mathrm{Fe}_{2} \mathrm{O}_{3}$ nano heterojunctions: Mechanism Elucidation," Ceramics International, vol. 46, no. 8, pp. 12255-12268, 2020.

[35] R. Foroutan, R. Mohammadi, S. Farjadfard et al., "Characteristics and performance of $\mathrm{Cd}, \mathrm{Ni}$, and $\mathrm{Pb}$ bio-adsorption using Callinectes sapidus biomass: real wastewater treatment," Environmental Science and Pollution Research, vol. 26, no. 7, pp. 6336-6347, 2019.

[36] M. Rafatullah, O. Sulaiman, R. Hashim, and A. Ahmad, "Adsorption of copper (II), chromium (III), nickel (II) and lead (II) ions from aqueous solutions by meranti sawdust," Journal of Hazardous Materials, vol. 170, no. 2-3, pp. 969977, 2009.

[37] Z. Zhang, T. Wang, H. X. Zhang, Y. H. Liu, and B. S. Xing, "Adsorption of $\mathrm{Pb}(\mathrm{II})$ and $\mathrm{Cd}(\mathrm{II})$ by magnetic activated carbon and its mechanism," Science of The Total Environment, vol. 757, p. 142910, 2020.

[38] E. Mabrouk, H. Wiem, K. Nejib, and B. Mourad, "Wastewaters decontamination: mechanisms of $\mathrm{Pb}$ (II), $\mathrm{Zn}$ (II), and Cd (II) competitive adsorption on Tunisian smectite in single and multi-solute systems," Environmental Progress and Sustainable Energy, vol. 32, pp. 229-238, 2013.

[39] J. Maity and S. K. Ray, "Chitosan based nano composite adsorbent-synthesis, characterization and application for adsorption of binary mixtures of $\mathrm{Pb}(\mathrm{II})$ and $\mathrm{Cd}(\mathrm{II})$ from water," Carbohydrat. Polymers, vol. 182, pp. 159-171, 2017.

[40] J. X. Yu, L. Y. Wang, R. A. Chi, Y. F. Zhang, Z. G. Xu, and J. Guo, "Competitive adsorption of $\mathrm{Pb}^{2+}$ and $\mathrm{Cd}^{2+}$ on magnetic modified sugarcane bagasse prepared by two simple steps," Applied Surface Science., vol. 268, pp. 163-170, 2013.

[41] K. BHATTACHARYYA and S. S. Gupta, "Kaolinite and montmorillonite as adsorbents for $\mathrm{Fe}(\mathrm{III}), \mathrm{Co}(\mathrm{II})$ and $\mathrm{Ni}(\mathrm{II})$ in aqueous medium," Applied Clay Science, vol. 41, no. 1-2, pp. 1-9, 2008. 